\title{
Mechanical strength of sutured block copolymers films for load bearing medical applications
}

\author{
Joanna Stasiak $^{\mathrm{a}, *}$, Sukumaran Nair ${ }^{\mathrm{b}}$ and Geoff D. Moggridge ${ }^{\mathrm{a}}$ \\ ${ }^{a}$ Department of Chemical Engineering and Biotechnology, University of Cambridge, Pembroke Street, \\ Cambridge CB2 3RA, UK \\ ${ }^{b}$ Papworth Hospital NHS, Papworth Everard, Cambridge BC23 3RE, UK
}

\begin{abstract}
The mechanical behavior of three styrenic thermoplastic block copolymer elastomers with applied surgical sutures was studied by uniaxial tensile testing. The materials exhibited oriented cylindrical microstructure. Distinct macroscopic deformation mechanisms have been observed upon stretching of samples with vertical and horizontal orientation. Deformation progressed along the axis of the suture in samples with parallel orientation $(\mathrm{P})$, while it in case of normal orientation (N) the whole sample responded to the applied force. Also the analysis of the stress-strain curves showed a significant difference between samples P and N. Greater stress at break was observed for samples P, while samples N showed the capability to tolerate higher strain. The influence of morphology on the tear-out shape has been also observed. The thread made a vertical tear out in samples $\mathrm{P}$ while for samples $\mathrm{N}$ ripping off the bottom was observed.
\end{abstract}

Keywords: biomaterials, heart valves, sutures, mechanical behavior

\section{Introduction}

Cardiac valves, whether natural structures or biological or mechanical prostheses, are subjected to mechanical stress exerted by the blood flow. The material used for heart valve prosthesis must demonstrate a capacity to support this stress. The new generation bileaflet mechanical prostheses can easily withstand the stress, but their drawback is a risk of bleeding and thromboembolic complications [1-3]. Tissue based bioprostheses are less durable and tissue failure as well as calcification are their major weaknesses $[4,5]$. Thus producing a reliable cardiac prosthesis has led many authors to concentrate their studies on the development of biocompatible soft polymeric materials [6-12] with potential to overcome the limitations of these existing clinical prostheses. As natural heart valve tissue exhibits anisotropic fibrous texture, in which collagen bundles reinforce the structure, it is possible that materials mimicking such natural structural anisotropy will resist the stress better than isotropic ones.

Block copolymers can form various morphologies as a result of microphase separation. Elastomers with a hard cylindrical segment exhibit a fibrous microstructure on the scale of nanometers. When this microstructure is oriented the strength of these materials is significantly different than for isotropic

\footnotetext{
*Corresponding author. E-mail: js744@cam.ac.uk
} 
materials $[13,14]$. To the group of block copolymers demonstrating anisotropic mechanical properties belong, among others, block copolymers having a polystyrene hard (cylindrical) segment and a rubbery matrix, based on either isoprene/butadiene or isobutylene/ethylene-butylene. The materials behave like vulcanized rubbers at room temperature, and yet can be processed as thermoplastics at elevated temperatures. High tensile strength, high elongation and rapid and almost complete recovery after elongation [15] in addition to good biocompatibility [16,17] make them promising materials for cardiac grafts and prostheses.

In a commercial prosthesis different types of materials are employed, for example biological tissue, textile sewing ring, polymers, sutures joining the tissue to a stent; therefore successful functioning of the prosthesis depends on the reliability of all the components. When two materials of different elasticity are combined, the applied load generates cutting stress, damaging the structure. The greater the difference in the elastic behaviours of these two materials, the higher is the stress. A polymeric cardiac prosthesis can be moulded in one piece with integrated leaflets, stent and sewing ring made from the same material and chemically bonded together. Such an approach can limit the risk of component integrity failure. Nonetheless the prosthesis must be placed in the cardiac position by surgical suturing. Hence examination of the strength of sutured materials is essential for the evaluation of the reliability of such prostheses.

In this paper we report uniaxial tensile tests of three polymeric materials with applied surgical stitches. The materials exhibited aligned cylindrical microstructure. The tear-out characteristic and the hole formation were examined as a function of direction of microstructural alignment. The literature is mainly focused on examination of mechanical behaviour of sutured biological materials for cardiac bioprostheses, with leading contributions by Garcia Paez at al. [18-24]. There are no reports on tensile testing of sutured synthetic materials for soft polymeric cardiac prosthesis. Owing to a growing interest in the application of these new biomaterials there is a clear need to investigate the suture-material interaction upon load.

\section{Experimental}

\subsection{Materials}

Three thermoplastic styrenic block copolymers were examined. All are linear block copolymers exhibiting cylindrical microstructure. Basic molecular properties of these polymers are presented in Table 1. SI-BS19 and SIS were manufactured by Kraton Polymers (commercial names D1171 PT and D1164P), while SIBS30 was obtained from Innovia LLC.

Table.1.

Characterization of materials, Mw- molecular weight

\begin{tabular}{llll}
\hline Material & Full name & $\begin{array}{l}M_{w}, \\
\mathrm{~kg} / \mathrm{mol}\end{array}$ & $\begin{array}{l}\text { Polystyrene, } \\
\text { fraction, wt \% }\end{array}$ \\
\hline SI-BS19 & polystyrene-block-polyisoprene-block-polybutadiene-block- & 180 & 19 \\
SIS30 & polystyrene & 131.2 & 30 \\
SIBS30 & polystyrene-block-polyisoprene-block-polystyrene & 102.4 & 30 \\
\hline
\end{tabular}




\subsection{Sample preparation and microstructure characterization}

Prior to tests, materials' microstructure has been oriented as described previously [13,14]. To measure the microstructural alignment Small Angle X-ray Scattering (SAXS) patterns were recorded using a Bruker Nanostar analytical X-ray system operating at $40 \mathrm{kV}$ and $35 \mathrm{~mA}$. The system was collimated by cross-coupled mirrors and pinhole optics. Specimens were placed $106 \mathrm{~mm}$ from the Nanostar 2-D detector.

The studied block copolymers exhibited cylindrical morphology, where styrene rich cylinders were distributed in an isoprene, butadiene or isobutylene soft matrix. Figure 1 presents SAXS images and integrated SAXS profiles for the examined block copolymers. The basal spacing of the domains was $27 \mathrm{~nm}$ for SI-BS19, $26 \mathrm{~nm}$ for SIS30 and $37 \mathrm{~nm}$ for SIBS30.

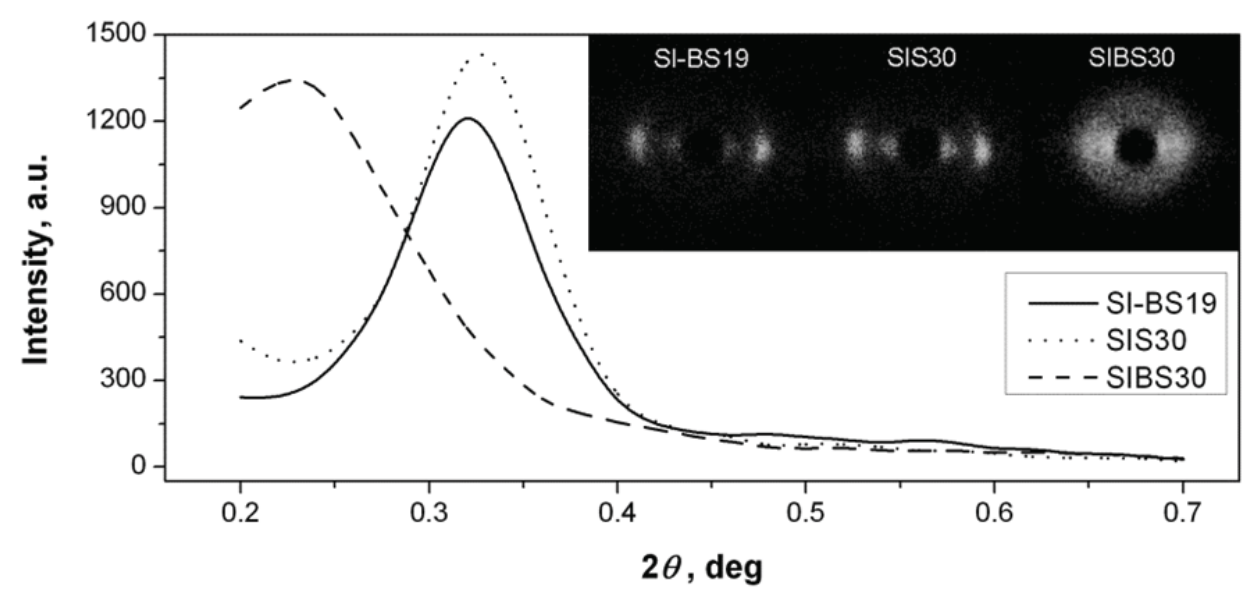

Fig. 1. SAXS images of oriented block copolymers and integrated SAXS profiles.

Two arrangements of orientation with respect to stretching direction were considered as shown in Figure 2. Sample $P$ exhibited vertical orientation which was parallel to direction of stretching, while sample $N$ showed horizontal alignment - normal to stretching direction.

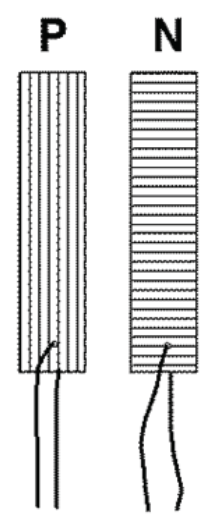

Fig.2. Microstructural orientation of the examined samples:

$\mathrm{P}$-perpendicular to stretching direction, N-normal to stretching direction. 
A commercially available thread, TiCron (non-absorbable braided polyester coated with silicone) was applied centrally $2 \mathrm{~mm}$ from the bottom of the sample. Samples were then clamped for stretching; thus the upper clamp held the sample and the lower clamp held the stitch. The tested samples after clamping were $10 \mathrm{~mm}$ long, $5 \mathrm{~mm}$ wide $0.35 \mathrm{~mm}$ thick. Stretching was performed at the rate $1 \mathrm{~mm} \mathrm{~s}^{-1}$ up to rupture of the materials while force in tension was measured using a Texture Analyzer TA-TX2 from Stable Micro System. A Qimaging QICam digital camera was used to record deformation of the polymer films.

\section{Results and discussion}

\subsection{Deformation mechanism as a function of microstructural alignment.}

During stretching, samples with two orthogonal directions of microstructural alignment exhibited distinct deformation mechanisms. Figure 3 shows images of deformed samples at various elongations that correspond to low, medium and near to rupture strain. The parallel orientation (sample $P$ ) caused significant elongation of the lower part of the sample below the thread. Moreover the macroscopic deformation propagated vertically along the line indicated by the position of the suture. Since the highest stress accumulated along the suture it eventually created vertical tearing out (see Figure 4).
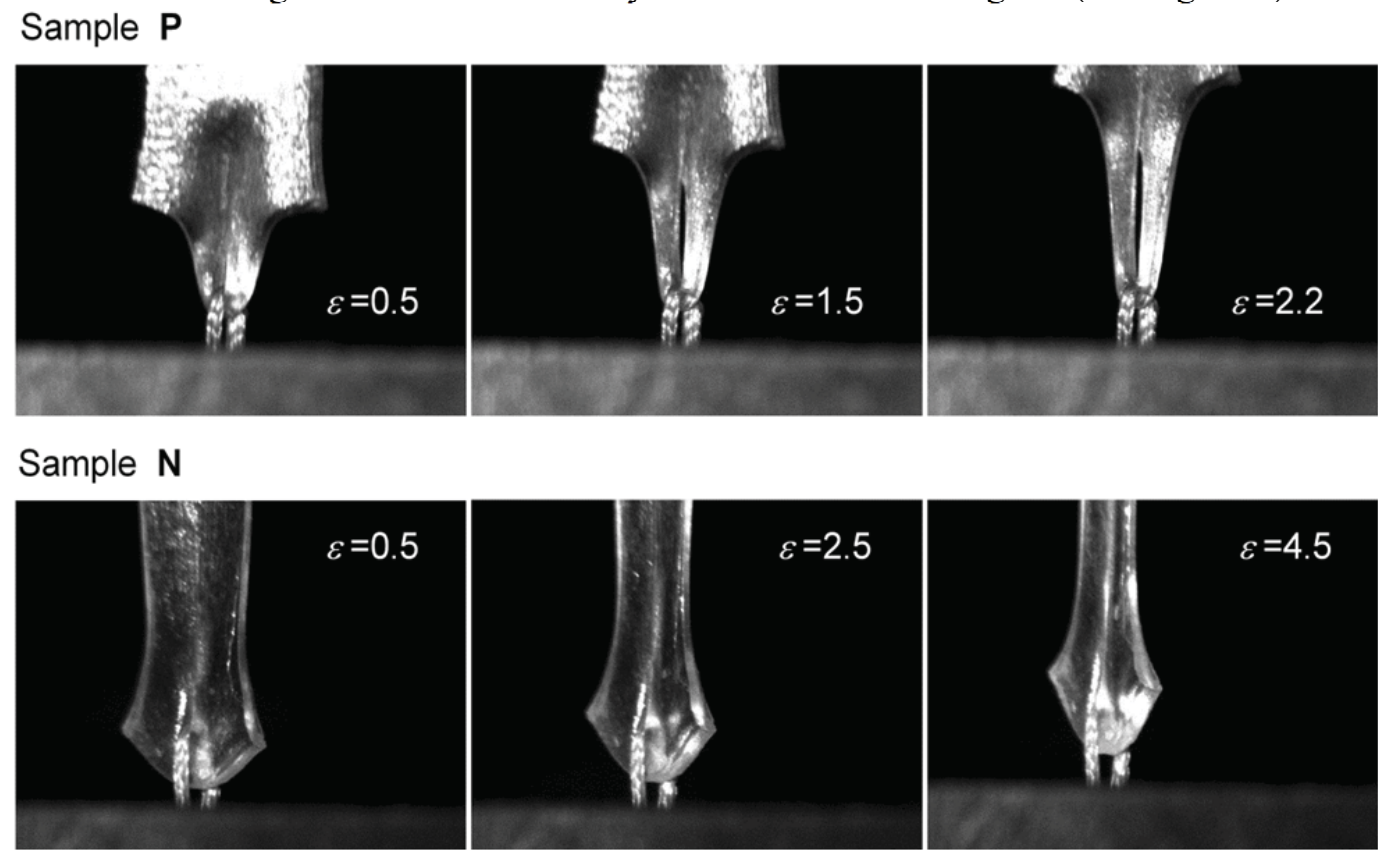

Fig.3. Propagation of deformation of sutured SI-BS19 as a function of alignment direction.

Conversely, for a sample with microstructure oriented normal to the stretching direction (sample $N$ ) the whole sample responded to the applied force and the deformation propagated uniformly within the sample. Only the lower part of the sample behaved differently being compressed by the thread upon elongation. Finally the suture caused tearing off the bottom part of the sample as shown in Figure 4. 

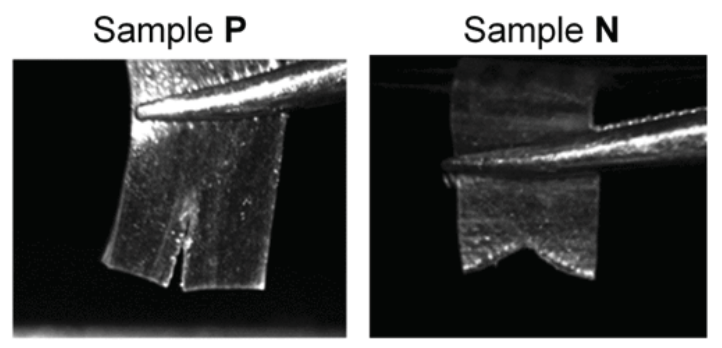

Fig. 4. Observed tearing models as a function of alignment direction.

These two distinct deformation mechanisms for samples $\mathrm{P}$ and $\mathrm{N}$ were observed for all three materials. In the case of the parallel orientation, the thread generated mostly local microscopic deformation of the sample. The applied force was mainly utilized for breaking of the styrenic cylinders. In the case of normal orientation the horizontally aligned cylinders acted as a scaffold for the rubber distributing the applied force within the whole sample. The force caused mostly elongation of the rubbery matrix.

\subsection{Mechanical tests}

The tensile tests were performed until rupture for 90 specimens: 15 measurements for each material and orientation were taken for statistical calculations. The example of stress-strain curves for various materials and microstructural orientation is shown in Figure 5. The plotted stress is an engineering stress (force divided by the initial cross sectional area of the sample) and strain $\varepsilon=\Delta L / L_{0}$, where $\Delta L$ is the increase of sample length and $L_{0}$ is the initial sample length. For all materials deformation of samples $P$ was associated with higher stress than for samples $N$. Moreover polymers having larger styrene fraction like SIS30 and SIBS30 had mean rupture stress of 5.0 MPa and 4.1 MPa respectively (Figure 6) which was about twice as high as the $2.2 \mathrm{MPa}$ measured for the lower styrene contents polymer (SI-BS19).
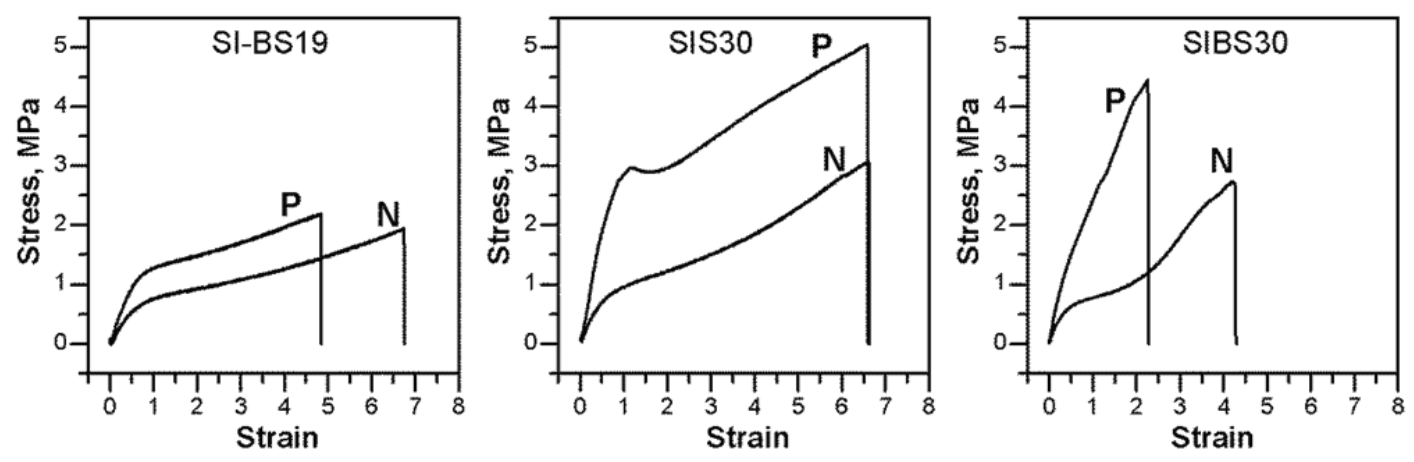

Fig. 5. Representative stress-strain curves for polymers with two fundamental alignment of microstructure.

On the other hand samples $N$ were capable to greater elongation before rupture compared to samples $P$. The largest mean breaking strain $\varepsilon=6.6$ was observed for the polymer with the lowest styrene fraction (SI-BS19).

Significant differences between the polymers were also observed in their tear-out behavior. Considering the mean stress at break and mean strain at break, the materials can be categorized into 3 groups as shown in Figure 6: SI-BS19 as a low strength-high elastic polymer, SIBS30 representing a high 
strength-low elasticity material, and SIS30 a high strength-high elasticity material. Such measurements are particularly important for applications where a combination of elasticity and strength determine the final performance of the device. Here we demonstrated that by engineering microstructural alignment both elasticity and strength can be tailored to meet individual requirements.

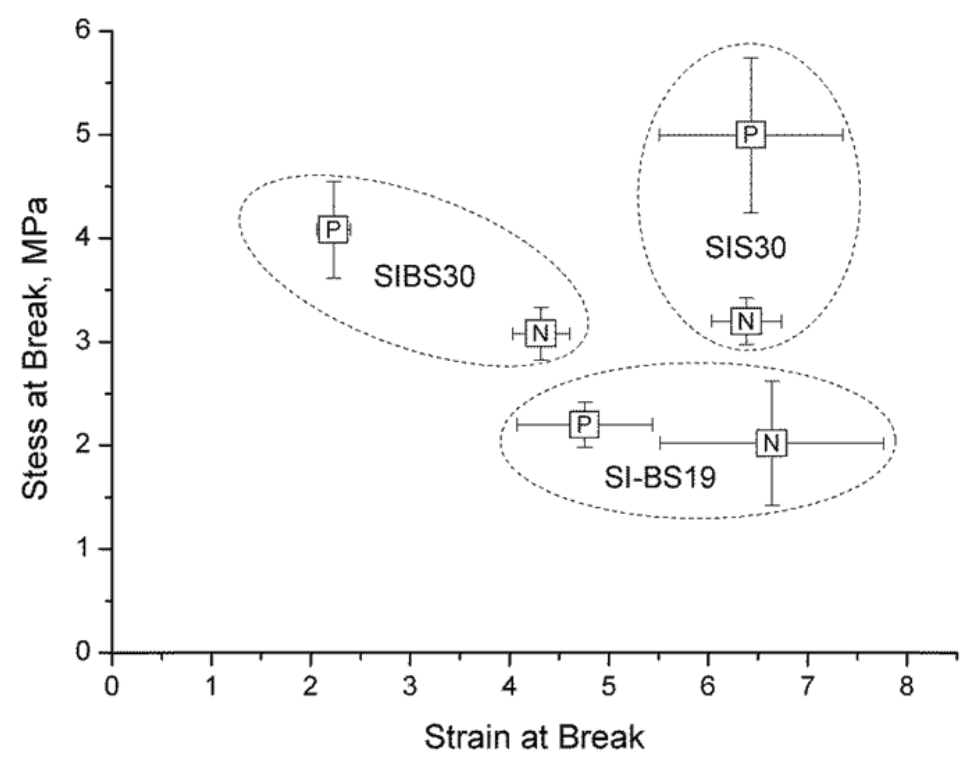

Fig. 6.Tear strength for examined materials and alignment direction.

\section{Summary}

Styrenic thermoplastic block copolymer elastomers having cylindrical morphology behave as fibre reinforced materials, similar to the native heart valve tissue. Alignment of the microstructure can further reinforce the materials. Additionally, the possibility of hot moulding of the whole cardiac prosthesis from the same material makes them very attractive for the application.

Here we reported tensile tests of sutured styrenic block copolymers having oriented microstructure. It has been shown that the deformation and tear out mechanisms are both functions of alignment direction. The influence of morphology on the breaking strain and breaking stress has also been reported. These findings are especially important for design and manufacture of sewing rings or stents for cardiac prosthesis.

Given that the blood pressure generates working stress in cardiac valve up to $0.25 \mathrm{MPa}$ during the systolic peak [25], even a single stitch could resist the stress and since twenty or so stitches are used to sew the prosthesis the materials seem to be very safe. However to complement this study the effect of suture density on materials' failure as well as various sewing angles should also be investigated.

\section{Acknowledgment}

The authors thank the British Heart Foundation for financial support for this work under Grant $\mathrm{NH} / 11 / 4 / 29059$. 


\section{References}

[1] K Hammermeister, G.K. Sethi, W.G. Henderson, F.L. Grover, C. Oprian, S.H. Rahimtoola, J Am Coll Cardiol 36 (2000), 1152-1158

[2] R.W. Emery, C.A. Erickson, K.V. Arom, W.F. Northrup, T.E. Kersten, T.J. Von Rueden, T.J. Lillehei, D.M. Nicoloff, Ann Thorac Surg 75(2003):1815-1819

[3] F.H. Bernet, D. Baykut, L. Grize, H.R. Zerkowski, J Heart Valve Dis 16(2007), 151-158

[4] W.B. Eichinger, I.M. Hettich, D.J. Ruzicka, K. Holper, C. Schricker, S. Bleiziffer, R. Lange, Ann Thorac Surg 2008;86(4):1204-1210

[5] Y.F. Chen, C.S. Lee, C.C. Lin, S.F. Su, M.L. Chen, C.C. Hsieh, H.M. Chen, C.C. Chiu, Y.H. Lu, H.Y. Liang, H.W. Yen, Y.S. Hwang, Y.T. Lin, J Cardiovasc Surg (Torino) 2003;44(6):691-699

[6] G.M. Bernacca, B. O’ Connor, D.F. Williams, D.J. Wheatley, Biomaterials 23(2002), 45-50

[7] Gillian M. Bernacca, Ian Straub, David J. Wheatley, J Biomed Mater Res. 61(2002):138-45

[8] S.L. Gallocher, A.F. Aguirre, V. Kasyanov, L. Pinchuk, R.T. Schoephoerster, J Biomed Mater Res B Appl Biomater. 79(2006), 325-334.

[9] T.E. Claiborne, G. Girdhar, S. Gallocher-Lowe, J. Sheriff, Y.P. Kato, L. Pinchuk, R.T. Schoephoerster, J. Jesty, D. Bluestein, ASAIO J. 57(2011), 26-31

[10] H. Ghanbari, H. Viatge, A.G. Kidane, G. Burriesci, M. Tavakoli, A.M. Seifalian, Trends Biotechnol. Jun;27(2009), 359-367

[11] A.G. Kidane, G. Burriesci, M. Edirisinghe, H. Ghanbari, P. Bonhoeffer, A. M. Seifalian, Acta Biomaterialia 5(2009), 2409-2417

[12] B. Rahmani, S.Tzamtzis, H. Ghanbari, G, Burriesci, A.M.Seifalian, J. Biomech. 45(2012), 1205-1211

[13] J. Stasiak, A. Zaffora, M. L. Costantino, A. Pandolfi, G. D. Moggridge, Funct Mater Lett, 3 (2010), 249-252

[14] J. Stasiak, A. M. Squires, V. Castelletto, I. W. Hamley, G. D. Moggridge, Macromolecules 42 (2009), 5256-5265

[15] J. Stasiak, A. Zaffora, M. L. Costantino, G. D. Moggridge, Soft Matter, 7(2011), 11475-11482

[16] M. El Fray, P. Prowans, J.E. Puskas, V. Altstadt, Biomacromolecules 7 (2006), 844-850

[17] J.M. Yang, S.C. Tsai, Mat. Sci. Eng C 30 (2010) 1151-1156

[18] J.M. Garcia Paez, A. Carrera San Martin, E. Jorge-Herrero, I. Millan, R. Navidad, I. Candela, J.V. Garcia Sestafe and J.L. Castillo-Olivares, Biomaterials 15 (1994), 172-176

[19] J.M. Garcia Paez, A. Camera San Martin, J.V. Garcia Sestafe, E. Jorge Herrero, R. Navidad, A. Cordon, J.L. CastilloOlivares, Biomoterials 17 (1996), 1677-1683

[20] J. M. Garcia Paez, A. Carrera, E. Jorge Herrero,I. Millan, A. Rocha, A. Cordon, N. Sainz, J. Mendez, J. L. CastilloOliveres, J. Biomater. Appl. 16 (2001), 68-90

[21] J. M. Garcia Paez, E. Jorge-Herrero, A.Carrera, I.Millan, A. Rocha, P. Calero, A. Cordon, N. Sainz, J. L. CastilloOlivares, Biomaterials 22 (2001) 2731-2740

[22] J. M. Garcia Paez, A. Carrera, E. Jorge Herrero, I. Millan, A. Rocha, A. Cordon, G. Tellez, M. Maestro, P. Calero, J. L. Castillo-Olivares, J. Biomed Mater Res 62 (2002), 73-81

[23] J.M. Garcia Paez, E. Jorge Herrero, A. Carrera Sanmartin, I. Millan, A. Cordon, M. Martin Maestro, A. Rocha, B. Arenaz, J.L. Castillo-Olivares, Biomaterials 24 (2003) 1671-1679

[24] J.M. García Páez, E. Jorge Herrero, M. Martín Maestro, A. Rocha, B. Arenaz, J.L. Castillo-Olivares, A. Carrera Sanmartín, A. Cordon, I. Millán, I., J. Mater. Sci. - Mater. Med. 14 (2003), 411-417

[25] P.L. Gould, A. Cataloguin, P.S. Dhatt, A. Chattopadhyay, R. Clark, Stress analysis of the human aortic valve, in: Computer and structures. London: Pergamon Press, 1973, vol. 3, pp. 377-384 